Gut, 1975, 16, 458-461

\title{
Assessment of simple methods of measuring intestinal transit times in children with gastroenteritis
}

\author{
R. H. HIGGS, R. B. ELLIS-PEGLER, AND H. P. LAMBERT \\ From the Communicable Diseases Unit, St George's Hospital, London
}

SUMMARY Intestinal transit times in children less than 3 years old with gastroenteritis were measured using carmine suspension and radioopaque pellets. Carmine transit times were short as expected in the acute illness, and lengthened on recovery to the values found in children without diarrhoea. Pellet transit times of the sick children were the same as those of controls without bowel disease. Solid markers may thus be misleading in acute diarrhoeal illness of childhood. Possible mechanisms are discussed.

Little is known about intestinal transit times in acute gastroenteritis. Two simple and harmless methods were chosen for assessment: carmine suspensions and radioopaque polystyrene pellets as described by Hinton, Lennard-Jones, and Young (1969). Eleven children under 3 years old with acute gastroenteritis were studied by both methods and compared with a control group of children also in hospital but with no abnormality of bowel function. A further group was studied using carmine both on admission and during convalescence.

\section{Children}

The children were all inpatients on the wards of the Communicable Diseases Unit at St George's Hospital, Tooting. Group 1 comprised 11 children with acute gastroenteritis studied on admission by both methods. They had a mean age of 9.5 months, ranging between 3 and 21 months. Group 2 was a control group of 11 children with a mean age of $17 \cdot 3$ months ranging from 5 to 35 months. This difference between the mean ages is significant $(t=22.2, P<0.05)$. The controls were inpatients without bowel disease or symptoms, and were passing solid motions with a frequency that their parents deemed normal. No child with 'parenteral diarrhoea' was admitted to this study. Group 3 consisted of 10 children with acute gastroenteritis who were assessed with carmine immediately on admission, and again during convalescence, when their stooling rate had returned to normal. This group includes one child (K) who was also studied in group 1 . All children acutely ill on admission were weighed on arrival and the percentage dehydration was calculated from the subsequent recovery plateau weight.

\section{Method}

\section{CARMINE}

This dye was administered as a suspension to the children with gastroenteritis as soon as possible after admission to the ward. A capsule containing $0.3 \mathrm{~g}$ of carmine was broken into the rehydration fluid, which consisted of 'half-strength Darrow's solution' (equal amounts of Darrow's solution and $5 \%$ dextrose) for those over 3 months old, and 'quarter-strength Darrow's' for those under this age. Control and convalescent children took the dye with one of their mid-morning drinks.

\section{PELLETS}

Radioopaque pellets of polystyrene were used as described by Hinton, Lennard-Jones, and Young $(1969)^{1}$. The pellets were cuboidal (approximately 2.7-3.0 $\mathrm{mm}$ in all dimensions) and weighed approximately $32 \mathrm{mg}$ each. The specific gravity of the material was $1 \cdot 20-1 \cdot 25$. The markers were given to groups 1 and 2 at the same time as the carmine. Thirsty children with diarrhoea usually swallowed them eagerly but some children in the control group took only eight pellets.

\section{RECOVERY OF SPECIMENS}

Each child with gastroenteritis was seated on a specially adapted 'Ekco baby-sitta' with a collecting pot beneath. The passage of each stool was recorded 


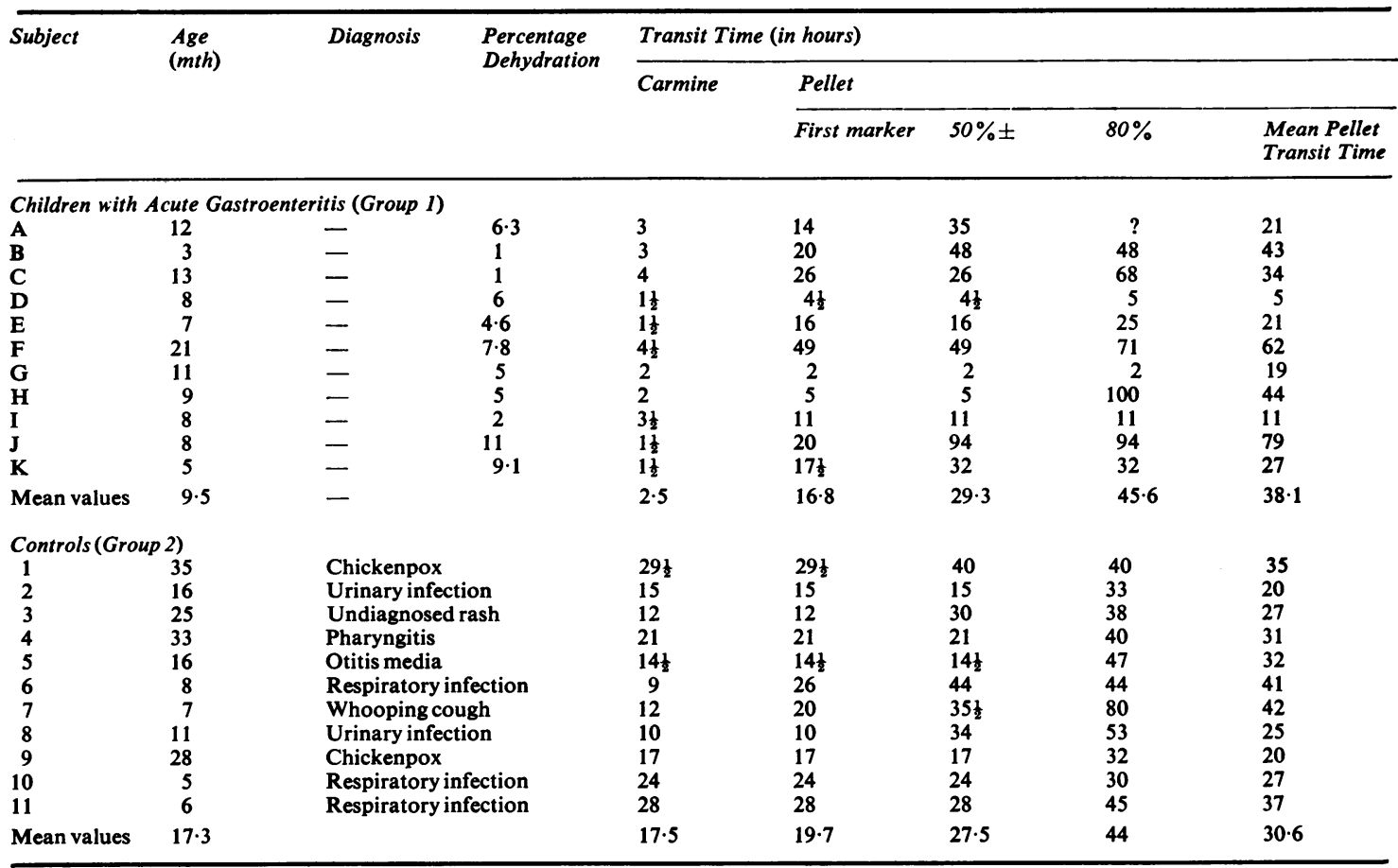

Table I Carmine and pellet transit times

by the presence or absence of carmine, and, if fluid the pellets were counted. The first stool was tested by Clinitest tablets for reducing substances, $0.5 \%$ or more being recorded as positive. Solid stool or napkin containing solid stools were double bagged and taken in groups in black polythene containers for radiography. The numbers of markers in each stool were then counted from the $x$-ray plate.

\section{PERMISSION}

Permission was always obtained from the parents after a full explanation of the purpose of the study and the procedure. Where possible a nurse was present as witness.

\section{Results}

The results of the study are presented in tables I and II and illustrated in the figure. In the tables the time of the first appearance of carmine in the stool is recorded, but the disappearance proved too imprecise to be useful. Four times are recorded for the marker method: first pellet, $50 \%$ of pellets \pm 1 pellet, $80 \%$ of the pellets, and a mean pellet transit time for each child, calculated using the formula

$\frac{\mathrm{T} 1 \mathrm{~S} 1+\mathrm{T} 2 \mathrm{~S} 2----+\mathrm{TnSn}}{\mathrm{S} 1+\mathrm{S} 2----\mathrm{Sn}}$ where $\mathrm{T}$ represents

time from ingestion to collection of specimen and $\mathrm{S}$

\begin{tabular}{|c|c|c|c|c|c|}
\hline Subject & $\begin{array}{l}\text { Age } \\
\text { (mth) }\end{array}$ & $\begin{array}{l}\text { Percentage } \\
\text { Dehydration }\end{array}$ & $\begin{array}{l}\text { Acute Carmine } \\
\text { Time }\end{array}$ & $\begin{array}{l}\text { Convalescent } \\
\text { Time }\end{array}$ & $\begin{array}{l}\text { On } \\
\text { Day }\end{array}$ \\
\hline $\begin{array}{l}\mathbf{Z} \\
\mathbf{Y} \\
\mathbf{X} \\
\mathbf{W} \\
\mathbf{V} \\
\mathbf{U} \\
\mathbf{T} \\
\mathbf{S} \\
\mathbf{K} \\
\mathbf{O}\end{array}$ & $\begin{array}{r}6 \\
16 \\
31 \\
9 \\
3 \\
3 \\
26 \\
2 \\
5 \\
34\end{array}$ & $\begin{array}{c}12 \cdot 7 \\
8 \cdot 5 \\
11 \\
1 \\
1 \\
4 \cdot 9 \\
9 \\
1 \\
9 \cdot 1 \\
1\end{array}$ & $\begin{array}{c}14 \\
4 \\
1 \\
2 \\
7 \\
3 \frac{1}{2} \\
3 \\
7 \\
1 \frac{1}{2} \\
2 \frac{1}{2}\end{array}$ & $\begin{array}{r}19 \\
24 \\
6 \\
2 \\
12 \\
19 \\
23 \\
13 \\
17 \frac{1}{2} \\
18\end{array}$ & $\begin{array}{r}4 \\
5 \\
3 \\
2 \\
11 \\
9 \\
2 \\
4 \\
3 \\
4\end{array}$ \\
\hline Mean values & $13 \cdot 5$ & & $4 \cdot 6$ & $15 \cdot 4$ & \\
\hline
\end{tabular}

Table II Acute and convalescent carmine times in children with acute gastroenteritis (group 3) 
TRANSIT TIMES
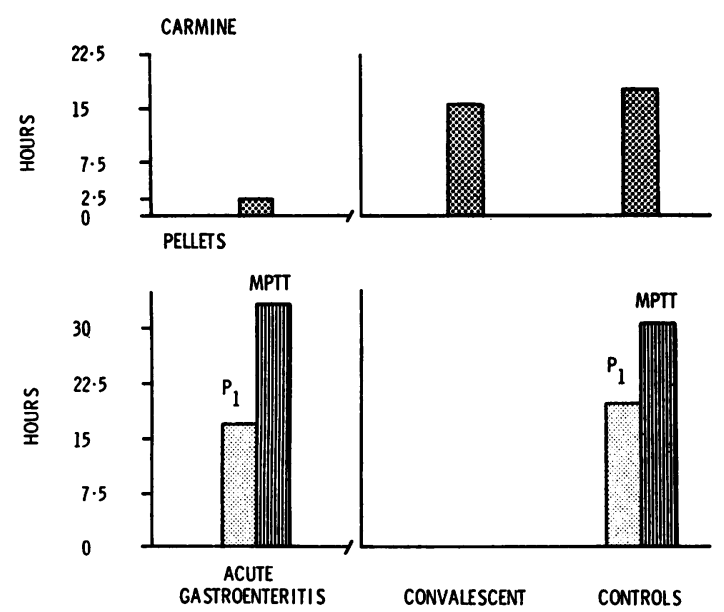

Fig. Transit times by carmine and pellet methods where $P_{1}=$ transit time of first pellet and MPTT $=$ mean pellet transit time.

the number of markers in the specimen for each collection. In group 3 transit times were assessed in convalescence by carmine only as it was not possible to study passage of the pellets again within the short inpatient time available.

No clear relationship was noted between transit time, percentage dehydration, and the presence of reducing substance in the stool.

\section{Discussion}

Most work on transit times in recent years has been concerned with adults or children with constipation. Methods applicable in acute childhood illness have not been evaluated. Studies in children under 3 years old with a transient and often self-limiting disorder demand a method of measurement that is accurate, easy to administer, perfectly safe and, if it is to be used widely, cheap. Some of the most accurate methods involve radioactive isotopes, such as ${ }^{51} \mathrm{Cr}$-labelled sodium chromate (Hansky and Connell, 1962) ${ }^{40}$ Lanthanum (Hayes, Carlton, and Nelson, 1964), and 131I (Rosswick, Stedeford, and Brooke, 1967). In all the radiation dose is small, but most paediatricians would consider the risk unacceptable. Polyethylene glycol (Borgström, Dalqvist, Lundh, and Sjövall, 1957) is used increasingly but is still too complex for this work. Hinton et al (1969) review further methods of this type.

Insoluble and non-absorbable coloured suspensions have been used for many years. Carmine was used in children by Triboulet (1909) and Lesné (1920) and in adults by Strauss (1914). Mulimos (1935) and Wolman (1957) note considerable variation in transit time and found, as we did, that the endpoint was difficult to define. Thus carmine, though cheap and very easy to use, is not as accurate a method as we should like when studying a disease in which transit time may be greatly reduced.

The method of Hinton et al (1969) using radioopaque markers had the advantages of safety and cheapness and promised to be more informative, as not only the beginning and end, but also the main bulk of the stool could be studied. Their work showed that in adults the first marker and carmine usually appeared simultaneously. Similarly in our control group (group 2) the first marker and the carmine arrived together in nine of the 11 children. The disappearance of carmine, though not easily quantifiable, broadly fitted with Dimson's (1970) findings in normal children. All subjects also passed $80 \%$ of their pellets by this time so that none of them were constipated by the definition of Hinton and Lennard-Jones (1968).

In the infants with gastroenteritis (group 1), however, widely divergent results are immediately apparent between the two methods. Sick children, often dehydrated and passing frequent fluid motions, were found by the carmine method to have rapid transit times consistent with the clinical picture (mean 2.5 hours with range one and a half to four and a half hours): but the first pellets were seen over a wide range (two to 49 hours, mean of 16.8 hours), similar to that found in the controls without diarrhoea (mean 19.7 hours, with a range 10 to $29 \frac{1}{2}$ hours). Other methods of measuring pellet transit time confirmed the anomaly; for example, the mean pellet transit times of the children with diarrhoea and of the controls are the same (33.1 hours and 30.6 hours respectively). The pellet method is clearly unsuitable for use in gastroenteritis.

Our findings might be explained by sequestration of pellets in a particular area of the bowel such as stomach or caecum, or as an example of streaming of gut contents into solid and liquid phases (Findlay, Mitchell, Eastwood, Anderson, and Smith, 1974). Pellets might be expected to travel in the slower solid phase. Carmine, as a solid suspension, is also usually regarded as a solid phase marker, but the consistently rapid carmine transit times we noted suggest that, in acute gastroenteritis, this substance travels with the liquid phase of the gut contents.

We wish to thank Sister Sheila Linton and the nursing staff of Frederick Hewitt Ward, Communicable Diseases Unit, St George's Hospital, London, SW17 for their help. R. B. Ellis-Pegler is the recipient of a research grant from the Wellcome Trust. We are 
most grateful to Dr G. Misiewicz and Dr J. H. Cummings for their helpful comments.

\section{References}

Borgström, B., Dalqvist, A., Lundh, G., and Sjövall, J. (1957). Studies of intestinal digestion and absorption in the human. J. clin. Invest., 36, 1521-1533.

Dimson, S. B. (1970). Carmine as an index of transit time in children with simple constipation. Arch, Dis. Childh, 45, 232-235.

Findlay, J. M., Mitchell, W. D., Eastwood, M. A., Anderson, A. J. B., and Smith, A. N. (1974). Intestinal streaming patterns in cholerrhoeic enteropathy and diverticular disease. Gut, 15, 207-212.

Hansky, J., and Connell, A. M. (1962). Measurement of gastrointestinal transit using radioactive chromium. Gut, 3, 187-188.

Hayes, R. L., Charlton, J. E., and Nelson, B. (1964). Lanthanum-140 as a measure of the completeness of stool collections. J. nucl. Méd., 5, 200-208.

Hinton, J. M., and Lennard-Jones, J. E. (1968). Constipation: definition and classification. Postgrad. med. J., 44, 720-723.

Hinton, J. M., Lennard-Jones, J. E., and Young, A. C. (1969). A method for studying gut transit times using radioopaque markers. Gut, 10, 842-847.

Lesnê, E., Binet, L., and Paulin, A. (1920). La traversée digestive chez le nourrisson variations biologiques et pathologiques. Arch. Méd. Enf., 23, 449.

Mulimos, M. G. (1935). The value of selective drugs in the treatment of constipation. Rev. Gastroent., 2, 292-301.

Rosswick, R. P., Stedeford, R. D., and Brooke, B. N. (1967). New methods of studying intestinal transit times. Gut, 8, 195196.

Strauss, H. (1914). Zur Verwendung der Karminprobe für die Bestimmung der Verweildauer im Verdauungskanal. Arch. Verdau.$k r ., 20,299$.

Triboulet, M. H. (1909). Durée de la transversée digestive chez l'enfant normal et chez l'enfant malade: epreuve du carmine. Bull. Soc. Pédiat., 11, 512-529.

Wolman, I. J. (1957). Laboratory Applications in Clinical Pediatrics p. 696. McCraw-Hill, New York. 